\title{
The Study of Reused Silica-Titania Catalyst on Biodiesel Production in Various Reaction Times
}

\author{
Syafira Ardana ${ }^{1}$, Ananda Putra ${ }^{1}$, Latisma DJ ${ }^{1}$, Rita Sundari ${ }^{2}$, Bahrizal ${ }^{1}$, Sri Benti Etika ${ }^{1}$, Umar \\ Kalmar Nizar*
}

${ }^{1}$ Chemistry Department, Universityy of Negeri Padang, Jl. Prof. Hamka, Air Tawar

Padang, West Sumatera, Indonesia

${ }^{2}$ Mechanical Engineering Department, Mercu Buana University, Jakarta, Indonesia

\begin{abstract}
This study has related to biodiesel production from Waste Cooking Oil (WCO) with reused silica-titania catalyst in various reaction times $(2-6 h)$. The reused silica-titania catalyst in this study has been obtained by washing the silica-titania waste released from the separation of catalyst and biodiesel product from palm and waste cooking oils in various reaction times. The washing silica-titania named by reused silica-titania has been characterized by DR UV-Vis to confirm the existence of titanium tetrahedral coordination. Meanwhile, the biodiesel product was characterized by FTIR and several properties such as density, flow rate and an acid number have been analyzed in order to study the reusability of silica-titania in biodiesel production. In addition, the results show that the fraction of titanium tetrahedral coordination in reused silica-titania catalyst (1st and 2 nd time) was found to be $26.11 \%$ and $24.02 \%$, respectively. The optimum reaction time was found to be $3 h$, which has been used for FTIR characterization to see significant absorption bands in the wavenumber range of $1300-1000 \mathrm{~cm}-1$. This range was attributed to absorption bands of $C-O$ ester from triglycerides and $C-O$ from carboxyl group. The main absorption FTIR bands of biodiesel products and WCO are relatively similar. The examinations of biodiesel properties with respect to density, flow rate, and acid number were conducted at optimum reaction time $(3 \mathrm{~h})$.
\end{abstract}

KeyWords: Reused silica-titania catalyst, Biodiesel, Transesterification, Titanium tetrahedral fraction.

\section{INTRODUCTION}

Biodiesel as one of renewable alternative energy sources was appropriate for diesel engine.This type of fuel can be applied directly in diesel engine without any previous modification. This type of biodiesel was advantageous in terms of renewable, biodegradable, nontoxic, non-sulfur, and less air pollutants. In addition, lubricating properties of this biodiesel was much better than that of diesel from fossil fuel and its properties are close to that of diesel from fossil fuel [1]

The waste cooking oil (WCO) is very potential to be applied as raw material for biodiesel production. The WCO is easily obtained from wastes of domestic and food industry. The oil waste can save land use and can be used for palm plantation to yield biodiesel. It should be noted that the properties of waste cooking oil (WCO) is not the same as that of fresh oil source due to hydrolysis of triglycerides yielding a lot of free fatty acids (FFA) [2], [3]. The transesterification is a reaction between triglycerides and short chain alcohol like methanol or ethanol with the usage of certain catalyst. Besides, the usage of methanol or ethanol for transesterification reaction is relatively low cost [4]. The transesterification process can use homogeneous or heterogeneous catalyst. The weakness point of homogeneous catalyst is that it cannot be regenerated because after using in reaction the removal of catalyst is difficult to be done related to high cost separation. In order to overcome the weakness of homogeneous catalyst and high cost, a heterogeneous catalyst is a good option for catalyzing transesterification reaction in biodiesel production and has already been applied in recent years [5].

The silica-titania $\left(\mathrm{SiO}_{2}-\mathrm{TiO}_{2}\right)$ was a binary oxide material grouping into heterogeneous catalyst. The silica-titania composite consists of silica acted as support or template and titania acted as catalyst center. This type of catalyst can increase surface area, thermal stability, and mechanical properties. The silica-titania material has already applied for photocatalysis, sensor material, and catalysis [6], [7]. As observed in many solid catalysts, the $\mathrm{SiO}_{2}-\mathrm{TiO}_{2}$ catalyst can be reused in biodiesel production 
with fulfilled one of requirements such as catalyst stability. This requirement is very substantial in biodiesel production because if the catalyst loss its stability yielding reduced catalytic performance for next usage [8]. This research group has already studied the optimization of reaction time in biodiesel production from palm and waste cooking oils applying silica-titania catalyst, which found percentage of conversion, i.e. $33.33 \%$ and $57.14 \%$ respectively, using optimum reaction time of 4h [9]. From the results of conversion, it can be deduced that silica-titania catalyst with its acid properties is effective and appropriate for vegetable oil with high FFA content like WCO. Up to date, the applicability of reused silica-titania catalyst in biodiesel production from WCO at varied reaction time has not been reported yet. Therefore, this study has been interested in studying the effect of reaction time on biodiesel production from WCO applying reused silica-titania catalyst.

\section{MATERIALS AND METHOD}

\subsection{Materials}

The materials are classified into materials for catalyst preparation and biodiesel production. The reused silica-titania catalyst was obtained by washing the catalyst used in the previous reaction. The solvens used for catalyst preparation were nhexane and methanol. The biodiesel production needed waste cooking oil, methanol, ethanol, $\mathrm{KOH}$, and pp indicator.

\subsection{Equipments}

The equipments used in this study included equipment for synthesis and characterization. For synthesis, this study needed glassware, hot plate stirrer, oven, balance, thermometer, stirrer, centrifuge and fumehood. Instrument used for characterization of silica-titania catalyst was DR UV-Vis spectrometer while the biodiesel product was characterized by FTIR spectrometer.

\subsection{Preparation of Reused $\mathrm{SiO}_{2}-\mathrm{TiO}_{2}$ Catalyst}

The reused catalyst in this study is that obtained from recycling previous silica-titania catalyst. The previously used silica-titania catalyst was washed by n-hexane to remove all non polar components adhered to the used catalyst for previous biodiesel production after optimization times reaction of and then the reused catalyst was dried. The catalyst after washing by nhexane was washed again by methanol to remove solven and all polar components attached to the catalyst and then dried . After washing by methanol, the catalyst was dried in an oven at $105^{\circ} \mathrm{C}$ for $2 \mathrm{~h}$ and stored inside desiccator before reused it for characterization and application. The second reused was conducted by the same procedure [10]

\subsection{Charaterization of Reused Silica-titania Catalyst}

The reused catalyst was characterized by DR UV-Vis in the range of $200-400 \mathrm{~nm}$. The spectra obtained were then deconvoluted using Gaussian function to calculate the number of titanium tetrahedral coordination in reused silica-titania

\subsection{Application of Reused Silica-titania Catalyst}

The catalytic activity of reused silica-titania catalyst was investigated in biodiesel production. The biodiesel production was done through transesterifrication reaction between waste cooking oil and methanol in the presence of reused silica-titania catalyst. The preparation of given silica-titania catalyst obtained from procedure 2.3 above was applied again in tranesterification reaction between WCO and methanol. The condition of reaction is based on optimum conditions obtained from previous research work [9]. Reaction between WCO and methanol based on mol ratio $6: 1$ conducted in a three bottle-neck Erlenmeyer (250 mL) in a reflux system at $65^{\circ} \mathrm{C}$ with varied reaction time of $2 \mathrm{~h}, 3 \mathrm{~h}, 4 \mathrm{~h}, 5 \mathrm{~h}$ and $6 \mathrm{~h}$. As many as $7 \%$ reused silica-titania catalyst was applied in this reaction. After the setting time reaction, the reaction product was the cooled and followed by separation of catalyst and excess methanol from the product. The reused silica-titania catalyst was separated by centrifuge while the excess methanol in product was conducted in rotary evaporator system at temperature above the boiling point of methanol. The same procedure was conducted for application of the $2^{\text {nd }}$ reused silica-titania catalyst [11].

\subsection{FTIR Characterization and Examination of Biodiesel Properties}

In order to get information the catalytic activity of reused silica-titania, as well as in relation to acid number and percentage of conversion, the biodiesel products from waste cooking oil were characterized by FTIR. In addition, several properties were also tested such as density, flow rate, and acid number. Then the results of properties examination were compared to that of waste cooking oil. All biodiesel products are summarized in Table 1 
International Journal of Advances in Scientific Research and Engineering (ijasre), Vol 5 (8), August-2019

Table1. Labeling biodiesel products

\begin{tabular}{|c|c|c|c|c|}
\hline \multicolumn{5}{|c|}{ Biodiesel Products } \\
\hline \multicolumn{3}{|c|}{$1^{\text {st }}$ reusability } & \multirow{2}{|c|}{$2^{\text {nd }}$ reusability } \\
Time (hour) & Label & & Time (hour) & Label \\
\hline 2 & BCR1-2H & 2 & BCR2-2H \\
\hline 3 & BCR1-3H & 3 & BCR2-3H \\
\hline 4 & BCR1-4H & 4 & BCR2-4H \\
\hline 5 & BCR1-5H & 5 & BCR2-5H \\
\hline 6 & BCR1-6H & & 6 & BCR2-6H \\
\hline
\end{tabular}

Note :

BCR1 :Biodiesel of $1^{\text {st }}$ catalyst reusability

$\mathrm{BCR} 2$ :Biodiesel of $2^{\text {st }}$ catalyst reusability

\section{RESUlTS AND DISCUSSION}

\subsection{The Stability of Titanium tetrahedral fraction in Reused Silica-titania Cataliyst}

The stability of reused silica-titania catalyst is very important factor because reduced stability can yield reduced catalyst performance resulting decreased catalytic action [12]. The reused catalyst needs to be characterized by DR UV-Vis before transesterification reaction in order to know the concentration titanium tetrahedral fraction in reused silica-titania catalyst (Fig.1).

\section{a. Reused silica-titania catalyst $\left(1^{\text {st }}\right)$}

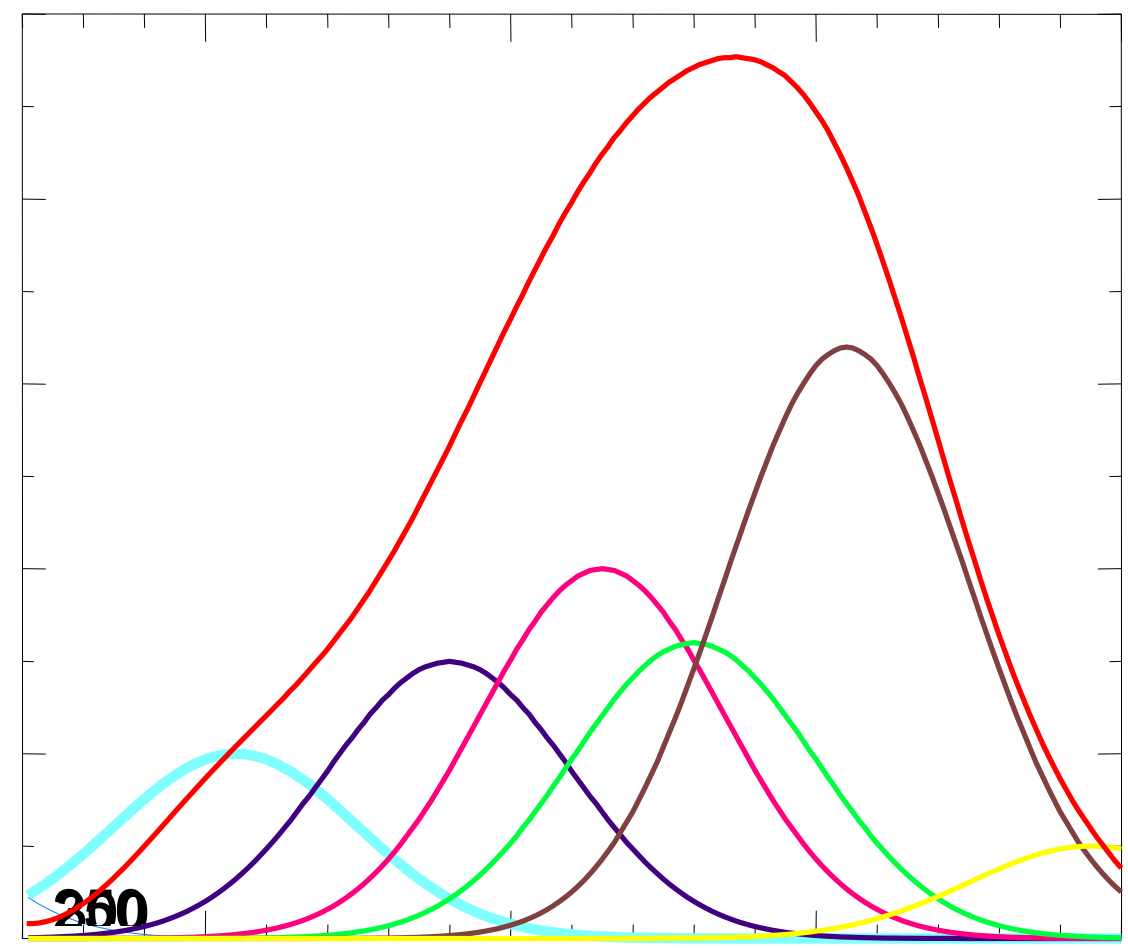

350

b. (b) 2nd reused silica-titania catalyst 


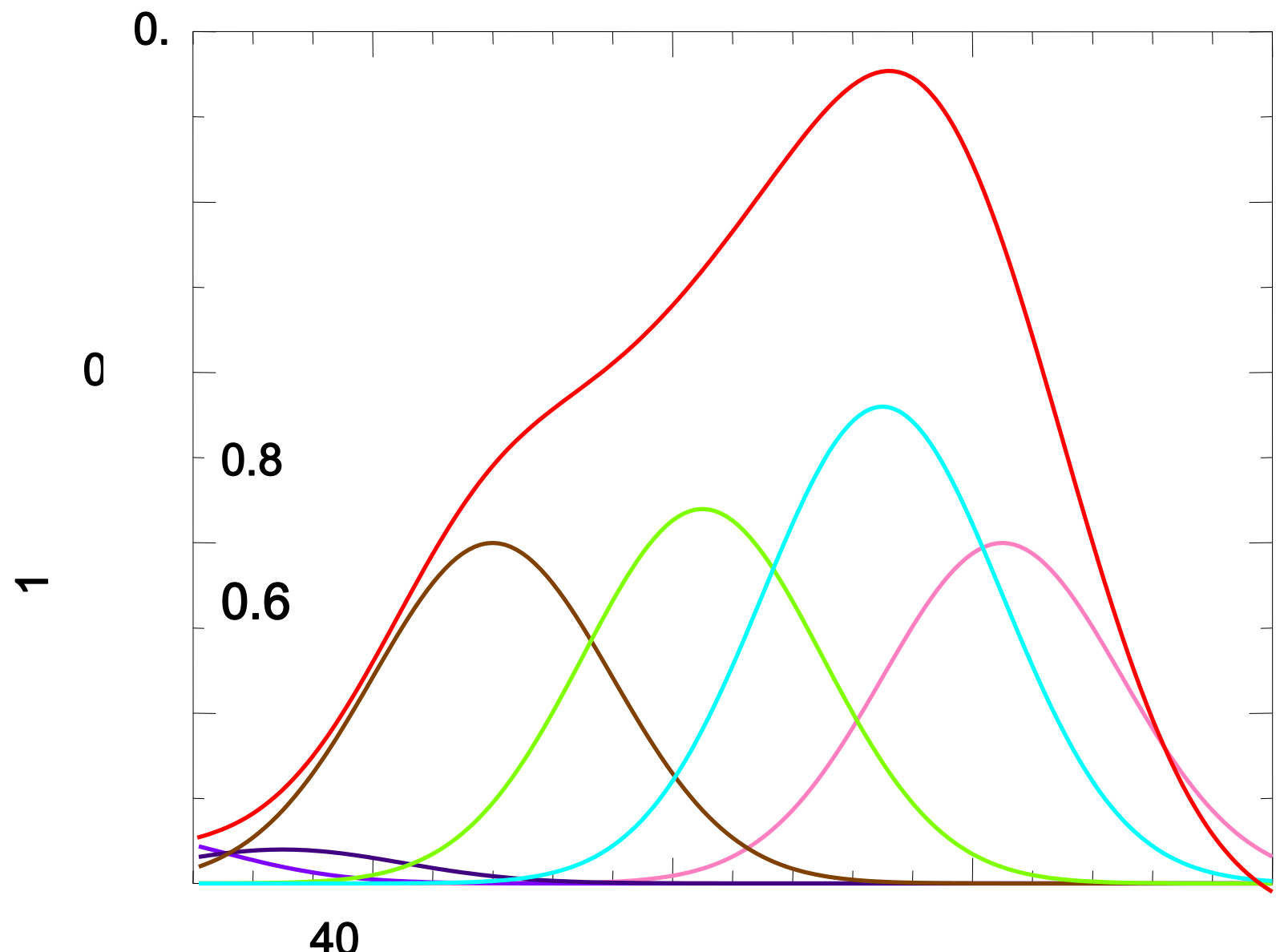

Figure 1.(a) $1^{\text {st }}$ reused and (b) $2^{\text {nd }}$ reused silica-titania catalyst

Figure1.Deconvolution spectra DR UV-Vis from

Literature study on DR UV-Vis spectra reported that titanium tetrahedral coordination area posed in wavelength range of $200-<285 \mathrm{~nm}$ and titanium octahedral coordination area posed in wavelength range higher than $285 \mathrm{~nm}$. The deconvolution of DR UV-Vis spectra of both reused silica-titania catalysts $\left(1^{\text {st }}\right.$ and $2^{\text {nd }}$ times) is presented in Fig.1, which showed fraction of titanium tetrahedral coordination in given catalysts $\left(1^{\text {st }}\right.$ and $2^{\text {nd }}$ time) found to be $26.11 \%$ and $24.02 \%$, respectively. These values are lower than that of previous given catalyst, i.e. $31.04 \%$ for biodiesel production reaction [11]. This finding indicated the Si-OTi bond unstable and collapsed during the given reaction times. Nevertheless, the fractions of titanium tetrahedral in both reused catalyst $\left(1^{\text {st }}\right.$ and $2^{\text {nd }}$ time) are still higher than that of commercial $\mathrm{TiO}_{2}(23.00 \%)[6]$

\subsection{Density}

It is known that density is a ratio value of weight of fuel to its volume at same temperature. The biodiesel yields from WCO generally have densities between $0.86-0.89 \mathrm{~g} / \mathrm{mL}$. The results of densities of biodiesel products at varied reaction time applying reused silica-titania catalysts $\left(1^{\text {st }}\right.$ and $\left.2^{\text {nd }}\right)$ are presented in Fig. 2, and the results showed a reduction of density from that of WCO $(0.879 \mathrm{~g} / \mathrm{mL})$ to biodiesel densities. 


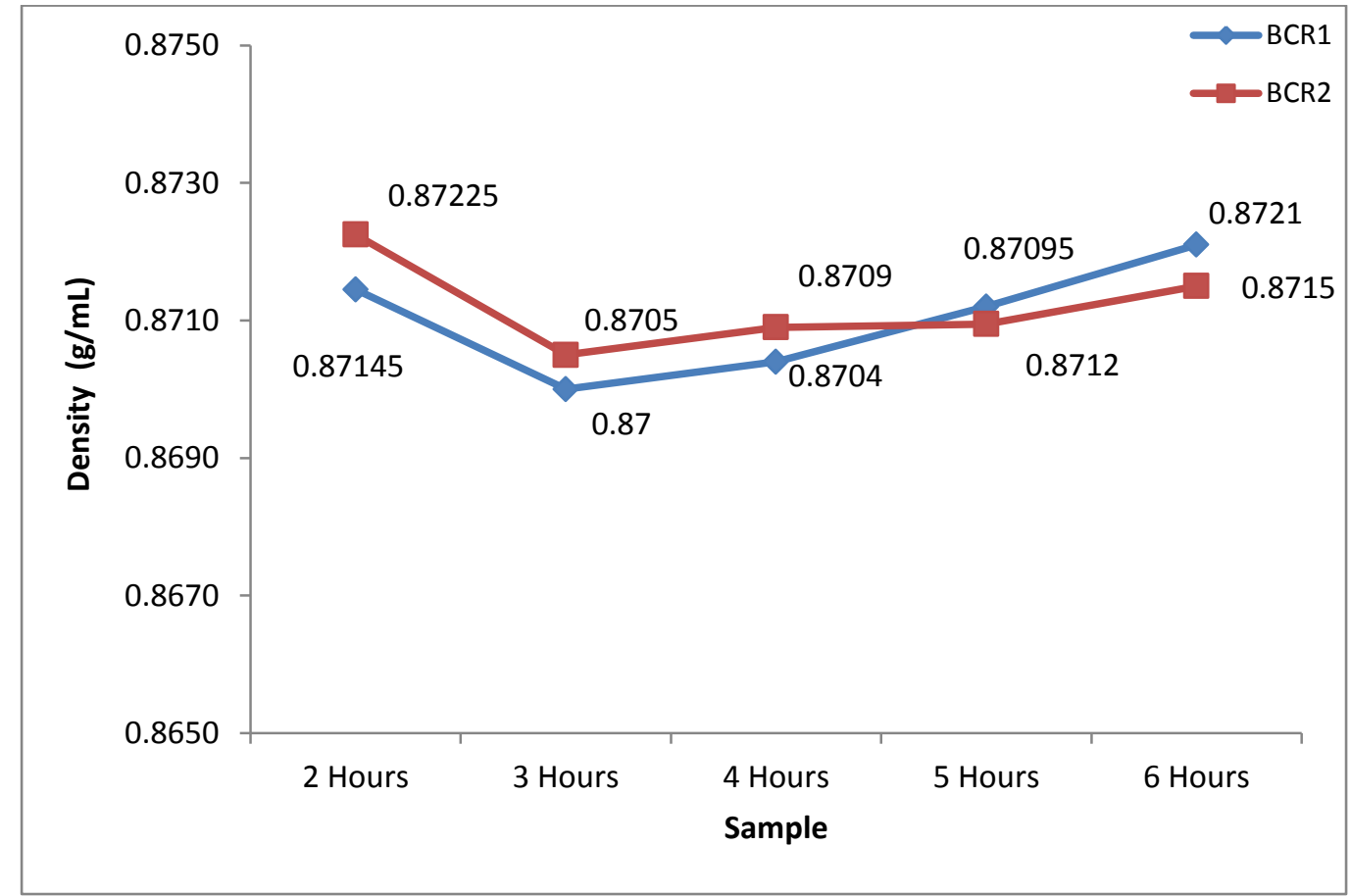

Figure2. Densities of biodiesel products from WCO

This study shows that optimum reaction time for BCR1 and BCR2 found to be the same, i.e. $3 \mathrm{~h}$, and the densities of BCR1 and BCR2 are found to be close by each other, i.e., $0.87 \mathrm{~g} / \mathrm{mL}$ and $0.8705 \mathrm{~g} / \mathrm{mL}$, respectively. The densities of biodiesel products are reduced until $3 \mathrm{~h}$ reaction time and after that, the densities getting increased again until reaction time of $6 \mathrm{~h}$. The densities getting increased until $6 \mathrm{~h}$ reaction time is due to increased reaction rate and equilibrium shift of reaction. Longer reaction yielded decreased biodiesel yield, this is corresponding with back reaction of transesterification. The reversed reaction yields product reduction due to part of methyl ester formed triglycerides again [13].

\subsection{Flow rate}

Flow rate is the second biodiesel properties to be assigned in this study to express its viscosity. Flow rate is the measured time required for a sample to flow. Viscosity is inversed proportional to its flow rate, or in other words, lower viscosity yields higher flow rate. The results of flow rate of biodiesel products at varied reaction time with addition of reused catalysts $\left(1^{\text {st }}\right.$ and $\left.2^{\text {nd }}\right)$ are presented in Fig. 4 and the results show an increase in flow rate of biodiesel product compared to that of WCO $(0.3032 \mathrm{~mL} / \mathrm{s})$.

It is observed that there is an increase of flow rate of biodiesel from given reaction time from $2 \mathrm{~h}$ to $3 \mathrm{~h}$ and followed by decreased flow rates until reaction time of $6 \mathrm{~h}$. Therefore, the optimum reaction time for respective BCR1 and BCR2 was found to be $3 \mathrm{~h}$. The flow rate values of both BCR1-3H and BCR2-3H were found to be $0.4926 \mathrm{~mL} / \mathrm{s}$ dan $0.3289 \mathrm{~mL} / \mathrm{s}$, respectively.

The flow rate of BCR1-3H is found to be different from that of BCR2-3H, this is related to difference of titanium tetrahedral fraction in reused silica-titania catalysts $\left(1^{\text {st }}\right.$ and $\left.2^{\text {nd }}\right)$. As already mentioned above that titanium tetrahedral fraction in reused catalysts $\left(1^{\text {st }}\right.$ and $\left.2^{\text {nd }}\right)$ were reported to be $26.11 \%$ and $24.02 \%$, respectively. This study found that flow rate of BCR $1-3 \mathrm{H}$ $(0.4926 \mathrm{~mL} / \mathrm{s})$ is higher than that of BCR2-3H $(0.3289 \mathrm{~mL} / \mathrm{s})$ that is consistent with concentration of titanium tetrahedral in reused catalyst $\left(1^{\text {st }}\right)$ i.e. $26.11 \%$, which is higher than that of reused catalyst $\left(2^{\text {nd }}\right)$ i.e. $24.02 \%$. Thus, in this event the higher titanium tetrahedral fraction is related to higher flow rate produced [11]. 
International Journal of Advances in Scientific Research and Engineering (ijasre), Vol 5 (8), August-2019

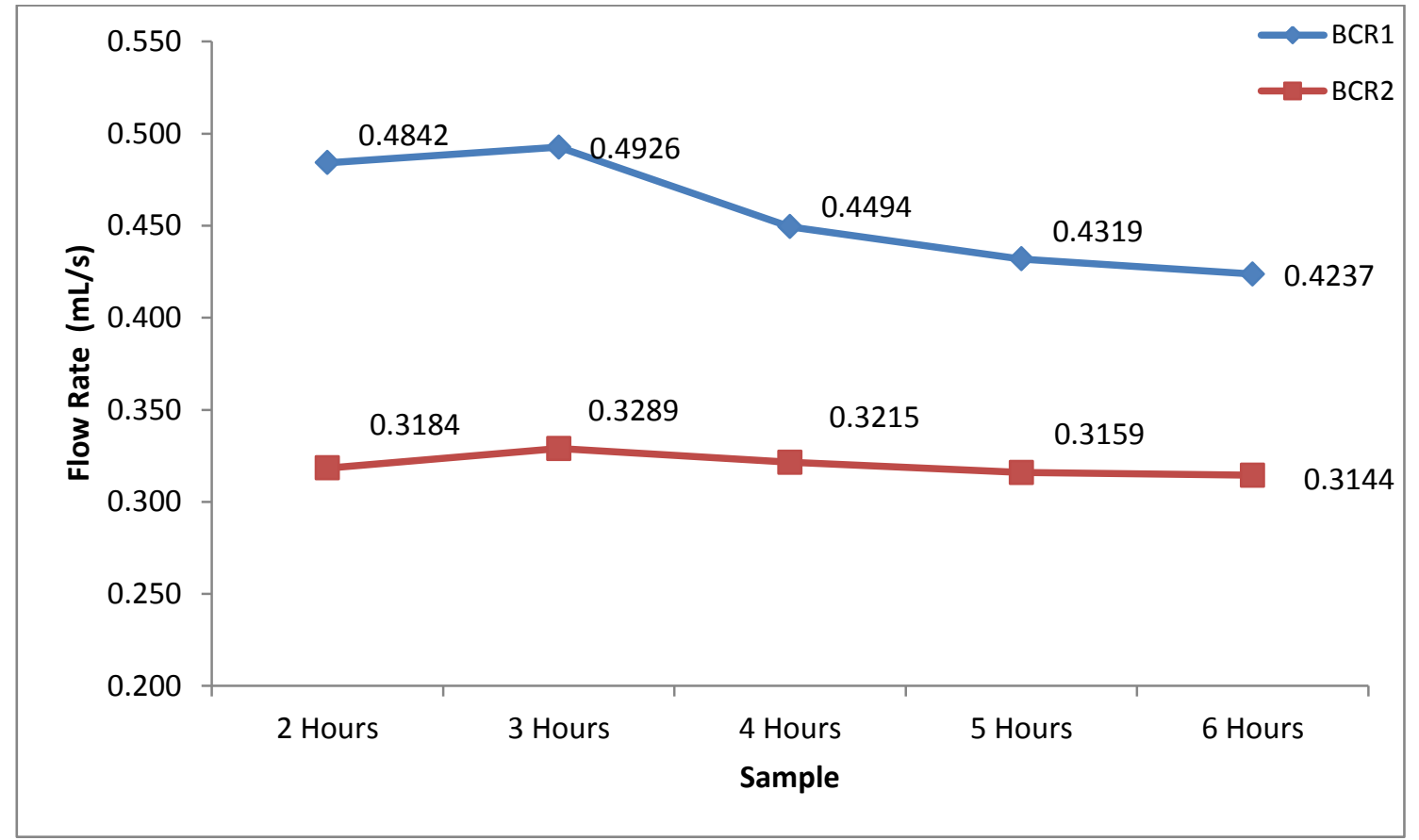

Figure3. Flow rates of biodiesel products from WCO

\subsection{Acid number and percentage of conversion.}

The determination of acid number is to know the content of FFA (free fatty acids) in biodiesel products. The acid number assay used acid base titration method. Based on the percentage of conversion of biodiesel product from WCO indicated that silicatitania catalyst is effective for vegetable oil with high FFA. The results of acid number at varied reaction time with addition of reused catalysts $\left(1^{\text {st }}\right.$ and $\left.2^{\text {nd }}\right)$ are presented in Fig.4. The results show a reduction in acid number of biodiesel compared to that of WCO (4.301 mg KOH/g).

The FFA content in WCO plays important role in transesterification reaction. High FFA content in raw material may yield soap formation. Soap formation reduced percentage of conversion to biodiesel and hindered separation and purification process of biodiesel product [14]

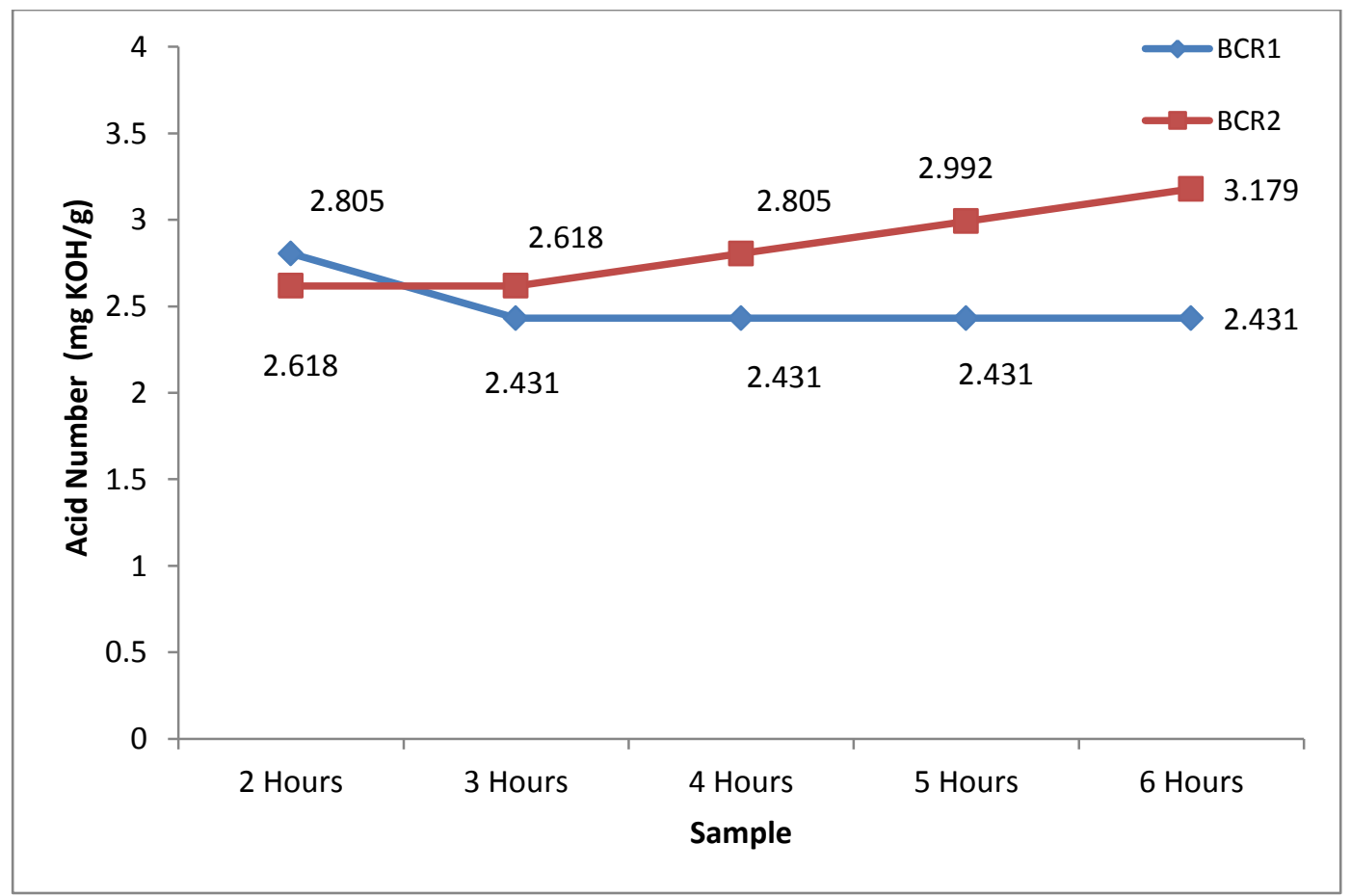

Figure4. Acid number of biodiesel products from WCO 
Table 1 and 2 show the results that at reaction time (3h) the percentage of conversion to BCR1-3H and BCR2-3H are to be $43,47 \%$ and $39,13 \%$, respectively. It should be noted for BCR2, that the highest percentage of conversion shown for reaction time of $2 \mathrm{~h}$ and $3 \mathrm{~h}$. However, based on consideration on density and flow rate of biodiesel products at related given time $(2 \mathrm{~h}$ and $3 \mathrm{~h}$ ), the optimum reaction time is taken to be $3 \mathrm{~h}$. The reduction in percentage of conversion to biodiesel is consistent with reduction in catalytic activity of reused silica titania catalysts. This finding is corresponding with titanium tetrahedral fractions in reused catalysts $\left(1^{\text {st }}\right.$ and $\left.2^{\text {nd }}\right)$ that are lower than that of previous silica-titania catalyst before reaction.

Table2. Acid number, \% FFA, and \% conversion ( BCR1 )

\begin{tabular}{|c|c|c|c|}
\hline Sample & Acid number & \% FFA & \% Conversion \\
\hline WCO & 4.301 & 2.1505 & $34.78 \%$ \\
\hline BCR1-2H & 2.805 & 1.4025 & $43.47 \%$ \\
\hline BCR1-3H & 2.431 & 1.2155 & $43.47 \%$ \\
\hline BCR1-4H & 2.431 & 1.2155 & $43.47 \%$ \\
\hline BCR1-5H & 2.431 & 1.2155 & $43.47 \%$ \\
\hline BCR1-6H & 2.431 & 1.2155 & \\
\hline
\end{tabular}

Table3. Acid number, \%FFA, and \% conversion ( BCR2 )

\begin{tabular}{|c|c|c|c|}
\hline Sample & Acid number & \% FFA & \% Conversion \\
\hline WCO & 4.301 & 2.1505 & $39.13 \%$ \\
\hline BCR1-2H & 2.618 & 1.3090 & $39.13 \%$ \\
\hline BCR1-3H & 2.618 & 1.3090 & $34.78 \%$ \\
\hline BCR1-4H & 2.805 & 1.4025 & $30.43 \%$ \\
\hline BCR1-5H & 2.992 & 1.4960 & $26.08 \%$ \\
\hline BCR1-6H & 3.179 & 1.5895 & \\
\hline
\end{tabular}

\subsection{FTIR spectra of WCO and biodiesel products.}

The FTIR characterizations are based on several considerations corresponding with respective biodiesel properties (lowest density, highest flow rate, acid number, and highest percentage of conversion) varied with reaction time. The FTIR spectra can be seen in Fig.5 with respect to spectra of WCO, BCR1-3H, and BCR2-3H related to optimum reaction time (3h). In general, the main absorption peaks of those spectra (WCO, BCR1-3H, and BCR2-3H) are similar at respective wave numbers of $2922,27 \mathrm{~cm}$ ${ }^{1}, 2857,45 \mathrm{~cm}^{-1}, 1742,81 \mathrm{~cm}^{-1}, 1455,67 \mathrm{~cm}^{-1}$ and $1159,63 \mathrm{~cm}^{-1}$. The absorption band of WCO at wave number of $1159,63 \mathrm{~cm}^{-1}$ is apparently sharper compared to that of biodiesel products, this is related to C-O-C and C-O-H groups in vegetable oil while only C-O-C group attributed to methyl ester (biodiesel)[3].

Table 4. presents main absorption bands with respect to important chemical bonding in WCO and biodiesel products. The FTIR of biodiesel spectra is undergone a little shift of wave number compared to that of WCO. The similarity between the FTIR spectra of WCO and biodiesel products is caused by similarity in structure of functional group building triglycerides in WCO and methyl ester group in biodiesel. The main absorption bands of FTIR spectra of WCO and biodiesel products (3h), which is substantially to be noted is that in the wave number range of $1300-1000 \mathrm{~cm}^{-1}$. This wave number range is corresponding with $\mathrm{C}$ $\mathrm{O}$ ester from triglycerides and $\mathrm{C}-\mathrm{O}$ from carboxyl group, and also $\mathrm{C}-\mathrm{O}-\mathrm{H}$ from FFA. The main absorption band of biodiesel in wave number range of $1300-1000 \mathrm{~cm}^{-1}$ is apparently broader than that of WCO [15] [11].

Absorption peaks at wavenumber range of $1300-1000 \mathrm{~cm}^{-1}$ attributed to C-O-C of methyl ester group, and weak absortion peaks at wavenumber range of $1600-1450 \mathrm{~cm}^{-1}$ attributed to C-C. Strong absorption peak at wavenumber range of 3000 $2800 \mathrm{~cm}^{-1}$ shows vibration of $\mathrm{C}-\mathrm{H}$ of methyl group [10]. The significant difference of the two FTIR spectra is the change of ester group of waste cooking oil to methyl ester group of biodiesel product, which is assigned by different of peak area in the range of $1300-1000 \mathrm{~cm}^{-1}$.

Table4. The significant absorption bands of WCO and biodiesel products.

\begin{tabular}{|c|c|c|c|}
\hline Type of bond & $\begin{array}{c}\text { WCO } \\
\text { absorption type }\left(\mathrm{cm}^{-1}\right)\end{array}$ & $\begin{array}{c}\text { BCR1-3H } \\
\text { absorption type }\left(\mathrm{cm}^{-1}\right)\end{array}$ & $\begin{array}{c}\text { BCR2-3H } \\
\text { absorption type }\left(\mathrm{cm}^{-1}\right)\end{array}$ \\
\hline $\mathrm{C}=\mathrm{O}$ & 1742,81 & 1742,05 & 1742,26 \\
\hline C-H & 2922,27 & 2922,06 & 2922,13 \\
\hline
\end{tabular}


International Journal of Advances in Scientific Research and Engineering (ijasre), Vol 5 (8), August-2019

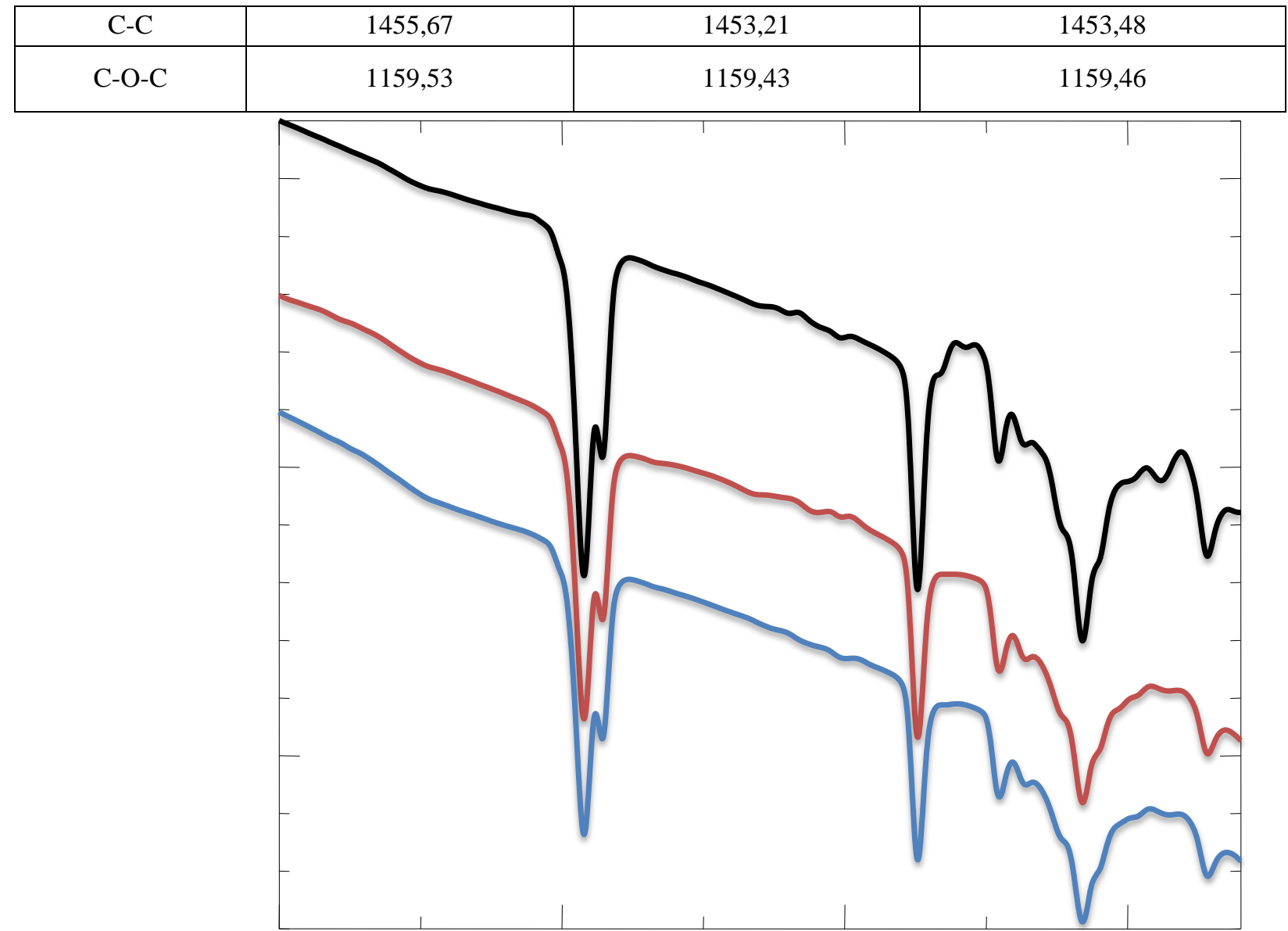

Figure5. FTIR spectra of WCO and biodiesel products

\section{Conclusion}

This study has justified that silica-titania catalyst is reusable. However the fraction of titanium tetrahedral in silica-titania decreased as increasing the number of catalyst reusability as shown by the results that the catalytic activity of reused silica-titania is getting lower than that previous given one. The optimum reaction time has obtained based on considerations on biodiesel properties (3h optimum reaction time) included density, flow rate, and acid number with its values consecutively as $0,87 \mathrm{~g} / \mathrm{mL}$, $0,4926 \mathrm{~mL} / \mathrm{s}$, and 2,431 mg KOH/g for BCR1-3H, and 0,87050 g/mL, 0,3289 mL/s, and 2,618 mg KOH/g for BCR2-3H.

\section{ACKNOWLEDGMENTS}

The author(s) would like to express gratitudes to the Directorate of Research and Community Service of UniversitasNegeri Padang, for their assistance in giving this Research Fund. The author(s) also express the deepest gratitude to Chemical Laboratory, Chemistry department, Faculty of Mathematic and Natural Science UniversitasNegeri Padang for providing support to this research.

\section{References}

[1] A. E. Atabani et al., "Non-edible vegetable oils: A critical evaluation of oil extraction, fatty acid compositions, biodiesel production, characteristics, engine performance and emissions production," Renew. Sustain. Energy Rev., 2013.

[2] S. K. Hoekman, A. Broch, C. Robbins, E. Ceniceros, and M. Natarajan, "Review of biodiesel composition, properties, and specifications," Renewable and Sustainable Energy Reviews. 2012.

[3] U. K. Nizar et al., "The Effect of Titanium Tetrahedral Coordination of Silica-Titania Catalyst on the Physical Properties of Biodiesel," in IOP Conference Series: Materials Science and Engineering, 2018. 
[4] N. S. Talha and S. Sulaiman, "Overview of catalysts in biodiesel production," ARPN J. Eng. Appl. Sci., vol. 11, no. 1, pp. 439-442, 2016.

[5] V. Singh, M. Yadav, and Y. C. Sharma, "Effect of co-solvent on biodiesel production using calcium aluminium oxide as a reusable catalyst and waste vegetable oil," Fuel, vol. 203, pp. 360-369, 2017.

[6] U. K. Nizar, J. Efendi, L. Yuliati, D. Gustiono, and H. Nur, "A new way to control the coordination of titanium (IV) in the sol-gel synthesis of broom fibers-like mesoporous alkyl silica-titania catalyst through addition of water," Chem. Eng. J., vol. 222 , pp. 23-31, 2013.

[7] R. S. et al. U. Nizar, J. Hidayatul, "The Effect of Titanium Tetrahedral Coordination of Silica-Titania Catalyst on the Physical Properties of Biodiesel The Effect of Titanium Tetrahedral Coordination of Silica- Titania Catalyst on the Physical Properties of Biodiesel," IOP Conf. Ser. Mater. Sci. Eng., vol. 335, no. 1, 2018.

[8] S. Alaei, M. Haghighi, J. Toghiani, and B. Rahmani Vahid, "Magnetic and reusable MgO/MgFe 2 O 4 nanocatalyst for biodiesel production from sunflower oil: Influence of fuel ratio in combustion synthesis on catalytic properties and performance," Ind. Crops Prod., vol. 117, no. September 2017, pp. 322-332, 2018.

[9] D. Farianty, A. Putra, L. Dj, and U. K. Nizar, "Biodiesel Production from Palm and Waste Cooking Oils Catalyzed by Silica-Titania Catalyst with Time Variation,” vol. 4, no. 7, pp. 4-8, 2019.

[10] J. Dantas, E. Leal, D. R. Cornejo, R. H. G. A. Kiminami, and A. C. F. M. Costa, "Biodiesel production evaluating the use

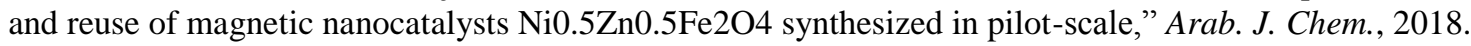

[11] Z. Zurryati et al., "The Effect of Silica-Titania Catalyst Loading on the Production of Biodiesel from Palm and Waste Cooking Oil Abstract :," Int. J. Sci. Res. Eng. Dev., vol. 2, no. 3, pp. 96-101, 2019.

[12] A. Bilgin, M. Gülüm, İ. Koyuncuoglu, E. Nac, and A. Cakmak, "Determination of Transesterification Reaction Parameters Giving the Lowest Viscosity Waste Cooking Oil Biodiesel," Procedia - Soc. Behav. Sci., vol. 195, pp. 24922500, 2015.

[13] H. G. Abubakar, A. S. Abdulkareem, A. Jimoh, O. D. Agbajelola, J. O. Okafor, and E. A. Afolabi, "Optimization of biodiesel production from waste cooking oil," Energy Sources, Part A Recover. Util. Environ. Eff., vol. 38, no. 16, pp. 2355-2361, 2016.

[14] M. Abdul Raqeeb, "Biodiesel production from waste cooking oil," J. Chem. Pharm. Res., vol. 7, no. 12, pp. 670-681, 2015.

[15] M. F. Elkady, A. Zaatout, and O. Balbaa, "Production of Biodiesel from Waste Vegetable Oil via KM Micromixer," Hindawi Publ. Corp., vol. 2015, 2015. 